УДК 005.5;353;354 J JEL M38

Зуденкова Светлана Александровна канд. экон. наук, ФГОБУ ВО «Финансовый университет при Правительстве Российской Федерации», г. Москва

e-mail: Zudenkova_s.a@mail.ru

\section{Zudenkova Svetlana}

Candidate of Economic Sciences, Financial University under the Government of the Russian Federation, Moscow

e-mail: Zudenkova_s.a@mail.ru

\section{ВОЗМОЖНОСТИ ИСПОЛЬЗОВАНИЯ ГИБКИХ МЕТОДОВ В ГОСУДАРСТВЕННОМ УПРАВЛЕНИИ}

Аннотация. Метод управления в значительной степени предопреде осущуествления управленческой деятельности, а значит и резуль что представляет особую важность для государственного тье рассмотрены преимущества и особенности испол дов управления (Agile, Scrum, Kanban, Lean, Six sigm зования гибких методов в государственном упре Раскрыты отечественная практика и акту дарственном управлении в Российской

Ключевые слова: государственное у гибкие методы управления, про THE POSSIBILV
METHODS IV XIBLE

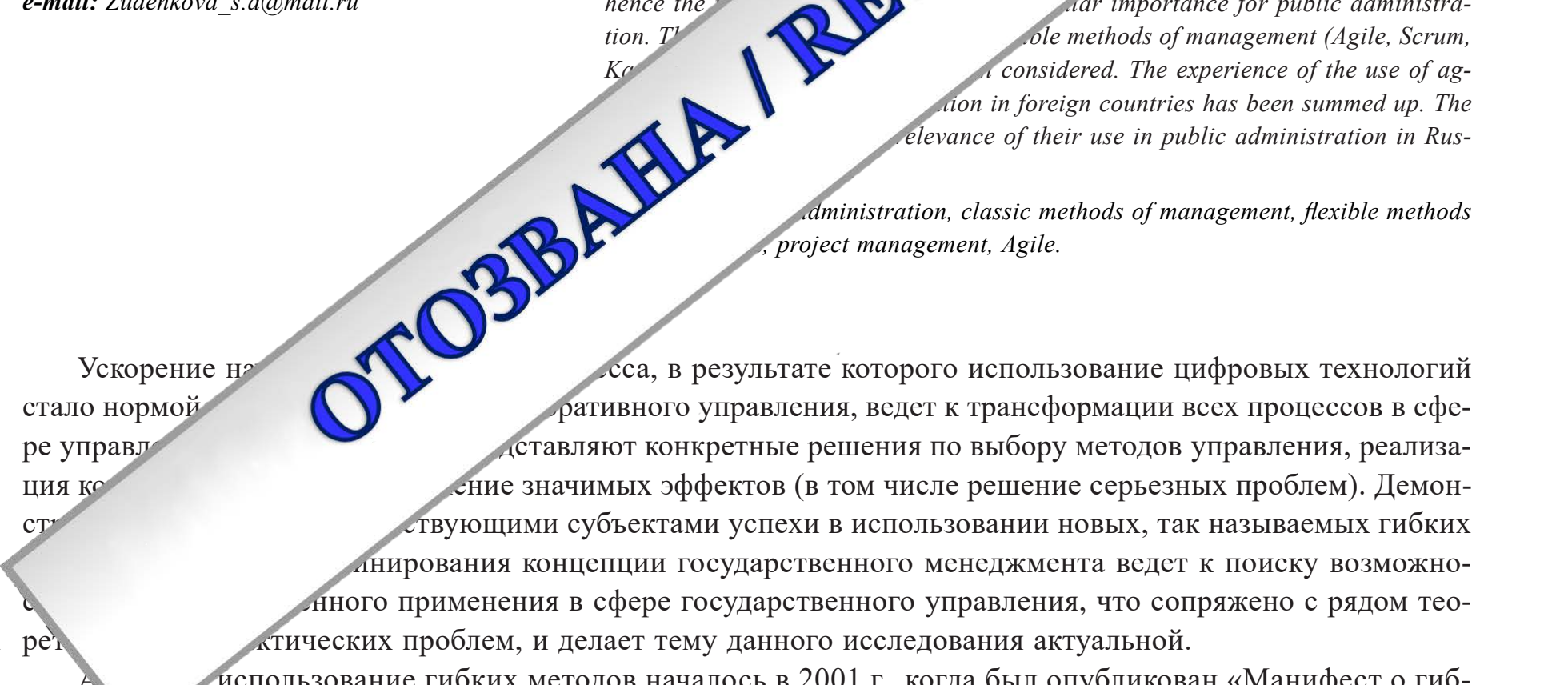
кой раз отке программного обеспечения Agile» (англ. Agile Manifesto), кратко отражающего принципы гибкой методологии [11]. Изначально методы Agile были ориентированы на участников проектной деятельности в информационно-технологической (далее - ИТ) сфере как методы разработки программного обеспечения и представляли собой набор рекомендаций, подготовленных руководителями компаний, программистами и консультантами по гибким методам [6]. Гибкие методы определяют через сравнение с классическим водопадным подходом к проектной деятельности. Постулатами гибких методов можно считать следующие:

- люди и взаимодействие важнее процессов и инструментов;

- работающий продукт важнее исчерпывающей документации;

(C) Зуденкова С.А., 2019. Статья доступна по лицензии Creative Commons «Attribution» («Атрибуция») 4.0. всемирная (http://creativecommons.org/licenses/by/4.0/).

The Author(s), 2019. This is an open access article under the CC BY 4.0 license (http://creativecommons.org/licenses/by/4.0/).

(c) (i) 
- сотрудничество с заказчиком важнее согласования условий контракта;

- готовность к изменениям важнее следования первоначальному плану [11].

Интересно, что манифест Agile появился не до, а после формулирования методов и подходов, вошедших в семейство Agile. «Старший» из методов, Kanban, был предложен еще в 1953 г., а самый распространенный - фреймворк Scrum - разработан в 1993 г. Гибкие методы управления представлены такими дами как Agile, Scrum, Lean, Kanban, Six sigma, что вызывает необходимость рассмотрения их под

Сущность Agile заключается в том, что каждый проект разбивается не на последовательные эт ни-проекты, которые впоследствии в сумме составят готовый продукт. Одним из дискусси относительно природы Agile является уяснение того, что это - метод управления проек методов управления проектами. Agile имеет определенное сходство с классическим проектами: этапы инициации и планирования осуществляются для всего мега-пr работка, тестирование, проверки проводятся уже для каждого мини-проекта ускоряет процесс выполнения поставленных в проекте задач. Главное до тивность. Agile отлично подходит к задачам, где очень высока степен крытый конец» (неизвестно точно приживется ли продукт в обш быть новые, инновационные и технологичные продукты. Одн ми, Agile требует индивидуального подхода каждого оргағ этих ценностей, что может оказаться очень длительны

Являясь последователем ценностей Agile и соче тается самым гибким и структурированным мет екта на части, самые важные из которых п 2-4 недели). По окончании этого этапа ? зовать (например, сайт в Интернете сле выполнения каждой части рағ
Метод Scrum предполага
чика, Scrum мастер - лил сле выполнения каждой части рағ
Метод Scrum предполага
чика, Scrum мастер - лил да - основное произв ла. Структура Scrum состоит из пяти основных процессов: встреча по упорял _oduct backlog процесс аналогичен этапу планирования в классическом упра ринта, ежедневные летучие собрания, подведение итогов спринта,

скорость работы. Метод ориентирован на «быстрые победы, быстрые

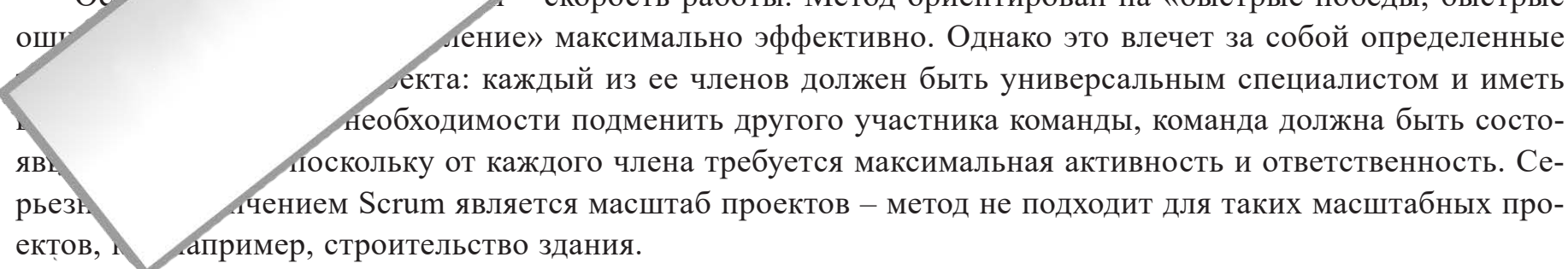

Среди особенностей метода Lean отсутствие четких границ каждого этапа и возможность параллельного выполнения различных задач (разных этапов), что в итоге повышает гибкость и скорость выполнения проекта. Фактически Lean дополняет Agile потоками операций для того, чтобы каждая из итераций выполнялась одинаково качественно. Lean предполагает чрезмерное внимание к каждой детали проекта, хотя зачастую этого и не требуется, что является большим минусом для крупных проектов. Также, в отличие от Scrum, Lean не задает строгого процесса выполнения работы, что может стать причиной растягивания сроков проекта.

Lean является частично абстрактным методом, но в комбинации с Кanban его очень просто использовать для управления проектами различной сложности. Кanban позволяет оставить задачу неоконченной на одном из этапов, если приоритет разработок изменился. Каnban менее требователен, чем Scrum: отсутствие точных сроков спринтов, регламента ежедневных встреч и т. д. Положительные стороны Капbаn - отсутствие точных сроков выполнения каждого этапа. Также, при правильном распределении нагрузки на каждого члена команды и грамотном управлении Kanban позволяет значительно сэкономить ресурсы, делать все точно в срок и не превышать бюджет проекта. Однако, Kanban, как и Scrum, очень требователен к членам команды. 
Метод Six sigma основывается на Lean, но больше внимания предполагает уделять стадиям п ния для экономии ресурсов, повышения качества, снижения количества брака. Структура Siy ит из 5 шагов DMEDI: определение (англ. Define), измерение (англ. Measure), исследовану разработка (англ. Develop), контроль (англ. Control). Six sigma следует реализовывать ных проектах, где необходима тщательная проработка каждой детали. С другой стог ного метода часто порождает путаницу в приоритетах, поскольку, делая ставку но сделать еще лучше» члены команды, зачастую не чувствуют удовлетвор

Проведенное исследование показало, что определенный (и положитель зования гибких методов накоплен в банковской сфере: Сбербанк, Аль'

Наибольших успехов во внедрении Agile в государственном упр В Великобритании существует 18 стандартов управления, в чис дов; также приняты требования к ИТ-проектам, которым Великобритании адаптирует Agile для крупных проекто тов создается по принципам Agile. Так, в Великобр тов стерлингов с 1 млн фунтов стерлингов благе за счет детального определения требований какой-то функционал, прописанный в в 2010 г. с проекта «Страж» в Феде 20 месяцев и составила всего 5 система управления базами п тодов - pесурс Healthcare циальных служб СШ запуска ресурс н ект за 3 месяу ние осуше

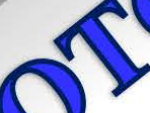
$n^{2}$

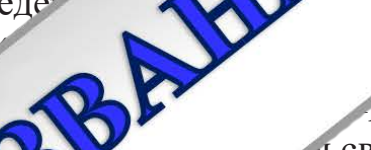
15 西 , 10 25 ование гибких метоование гибких метоработки. Правительство иия. Половина новых проекимость проекта на 80 тыс. фунa Agile [12]. Экономия происходит роекта, когда становится очевидно, что ША внедрение гибких методов началось ий (далее - ФБР). Реализация проекта заняла ом успешного внедрения Agile стала электронная ример проектной работы с использованием гибких месвязи базы данных Министерства здравоохранения и соственных учреждений и страховых компаний. После первого али по фреймворку Scrum, благодаря чему завершили весь пров отсу Ho O ддных организаций трудилась над своей задачей, а общее планировасетоду. Автор фреймворка Scrum Дж. Сазерленд видит причины неудачи вания проекта на этапах разработки и в разобщенности коллектива. Грамот- Подобно Великобритании, США, Австралии, Новой Зеландии и Италии, в июле д доставление цифровых услуг для департаментов и граждан с применением Agile [9; 10]. кой Федерации (далее - РФ) также имеются попытки использования гибких методов в государс. м управлении. Так, в апреле 2017 г. при Президиуме Совета при Президенте РФ по стратегическому развитию и приоритетным проектам появилась подгруппа по применению гибких подходов в государственных проектах, которая планировала проделать большую работу по изучению и совершенствованию нормативно-правовой базы, чтобы устранить барьеры для применения Agile в государственных проектах.

Интересен опыт Управления Пенсионного фонда России в Кировском и Промышленном районах г. Самара. Проектное управление в Пенсионном фонде Самарской области начали внедрять еще в 2015 г. [5]. Руководство управления (Е. Крюнькин) использовало симбиоз классических и гибких подходов. Так, из Scrum взяли инкрементно-итерационный метод, базовые термины и определения, а также артефакты доску задач, диаграмму сгорания, бэклог продукта и бэклог спринта; из Каnban позаимствовали принцип ограничения количества задач на одного человека, визуализацию производственного потока на доске задач; использовали элементы Lean Six Sigma, включая принцип работы «Быстро и качественно», оптимизацию рабочего пространства и производственных процессов. Всего было реализовано порядка 17 проектов, из которых следует выделить проект БОТиК по созданию Производственной системы и контакт-центра Пенсионного фонда, межведомственный проект по улучшению работы скорой медицинской помощи и проект «Бережливая поликлиника».

Среди преимуществ гибких методов управления следует отметить их большую открытость и восприимчивость к требованиям потребителей, т. к. разработчики и пользователи постоянно взаимодействуют друг с другом. Проект, создаваемый по методу Agile, лучше реагирует на любые изменения государственной политики в процессе разработки, например, на внесение изменений в действующие законы или принятие 
новых. Гибкие методы позволяют корректировать проект на любом этапе, есть также возможность вносить изменения после внедрения проекта согласно специальным методикам, предусматривающим изменения политики. Немаловажен такой аспект, как реагирование на технологические изменения, необходимое для адаптации сервисов и мобильных приложений.

Одной из причин внедрения Agile является экономия затрат на создание проекта, меньший риск сбоев, госкольку они выявляются на любом этапе, что проще, нежели пытаться устранить проблему на финальной с

Таким образом, в ходе реализации ряда проектов доказано, что использование гибких мет сударственном управлении не только возможно, но и необходимо. Безусловно, применение дов вызывает необходимость определенной перестройки работы органов управления и пример, обоснование необходимости отпускать подчиненного на часть или даже цел в работе команды проекта, что представляется одним из наиболее серьезных выз ориентированных на традиционные подходы к управлению. Однако при грам команды, при соблюдении принципов Agile, эти сложности с лихвой покр тельным эффектом от реализации проекта.

1. Андреева, Р. Н. SCRUM: гибкость в жестких рамках / Р. Н. Андре № 2. - C. 13-20.

2. Борисоглебская, Л. Н. Инновационные методы управлен масштаба Сбербанка / Л. Н. Борисоглебская, Е. И. Ш

3. Борисяк, Д. Греф признал неэффективность новог̆ тышев // Ведомости, 17.01.2016. - Режим дост neeffektivnost-it-platformi-sberbanka (дат?

4. Сазерленд, Дж. Scrum. Революцион и Фербер, 2016. - 288 с.

5. Управление проектами в сти upravlenie-proektami-v-

6. Agile Delivery. How доступа: https://

7. Agile Gove

8. Agile $\mathrm{J}^{\mathrm{T}}$

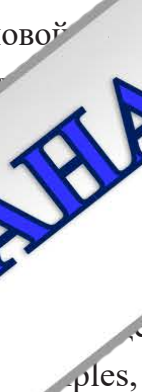
$\infty^{2}$ бй ресурс]. - Режим доступа: https://pm.center/company/news/ трансформация организации -2016. - № 12. - С. 139-142.

9. $\mathrm{Bir}^{\prime}$

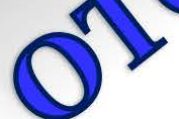

ples, tools and governance [Электронный pecypc] // Gov.UK. - Режим 1e-delivery\#phases-of-an-agile-project (дата обращения: 04.01.2019).

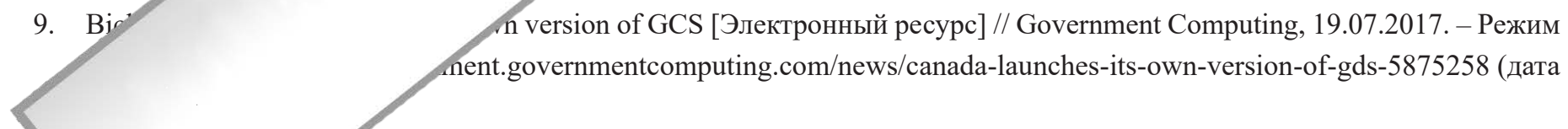
Changing Needs. - Canada's Public Policy Forum, 2015. - 20 p.

сктронный ресурс] // Government of Canada Publications, 2014. - Режим доступа: http://publications. collection_2014/bcp-pco/CP22-100-2014-fra.pdf (дата обращения: 04.01.2019).

11. M. Agile Software Development [Электронный ресурс]. - Режим доступа: http://agilemanifesto.org (дата обращен. 04.01.2019).

12. Scott, A. Agile Government in the UK [Электронный ресурс] // YouTube, 28.06.2016. - Режим доступа: https://www.уоutube. com/watch?v=Ey-iFQ4TT2A\&list=PLk8AWaxHcq7tgx0kQJe3OCXc3k3Dv1VO1\&index=1 (дата обращения: 04.01.2019).

\section{References}

1. Andreeva R. N, Sinyaeva O. YU. SCRUM: gibkost'v zhestkikh ramkakh [SCRUM: flexibility within a rigid framework], Vestnik universiteta, 2018, I. 2, pp. 13-20.

2. Borisoglebskaya L. N., Shikova E. I. Innovatsionnye metody upravleniya personalom: sistema Agile - transformatsiya organizatsii masshtaba Sberbanka [Innovative methods of personnel management: Agile system-the transformation organization scale the Savings bank], Vestnik universiteta, 2016, I. 12, pp. 139-142.

3. Borisyak D., Kantyshev P. Gref priznal neehffektivnost' novoi IT-platformy Sberbanka [Gref acknowledged the inefficiency of the new IT platform for the Savings bank], Vedomosti, 17.01.2016. Available at: https:/www.vedomosti.ru/finance/articles/2016/0 /18/624334-gref-priznal-neeffektivnost-it-platformi-sberbanka (accessed 04.01.2019). 
4. Sazerlend Dzh. Scrum. Revolyutsionnyi metod upravleniya proektami [A revolutionary method of project management], per. s angl. M. Geskinoi. M.: Mann, Ivanov i Ferber, 2016, 288 p.

5. Upravlenie proektami v stile «Samaradzhail» [Project management in the style of «Samaradzhayl»]. Available at: https://pm.center/company/news/upravlenie-proektami-v-stile-samaradzhayl/ (accessed 04.01.2019).

6. Agile Delivery. How to work in an agile way: principles, tools and governance. Gov.uk. Available at: https://www.gov vice-manual/agile-delivery\#phases-of-an-agile-project (accessed 04.01.2019).

7. Agile Government: Responding To Citizens' Changing Needs. Canada's Public Policy Forum, 2015, 20 p.

8. Agile IT Delivery: Imperatives for Government Success. Accenture Consulting, 2017, $34 \mathrm{p}$.

9. Bicknell D. Canada launches its own version of GCS. Government Computing, 19.07.2017. Available ment.governmentcomputing.com/news/canada-launches-its-own-version-of-gds-5875258 (accesc)

10. Destination 2020. Government of Canada Publications, 2014. Available at: http://publications bcp-pco/CP22-100-2014-fra.pdf (accessed 04.01.2019).

11. Manifesto for Agile Software Development. Available at: http://agilemanifesto.org (

12. Andrew Scott. Agile Government in the UK. YouTube, 28.06.2016. Available at.' T2A\&list=PLk8AWaxHcq7tgx0kQJe3OCXc3k3Dv1VO1\&index=1 (acce

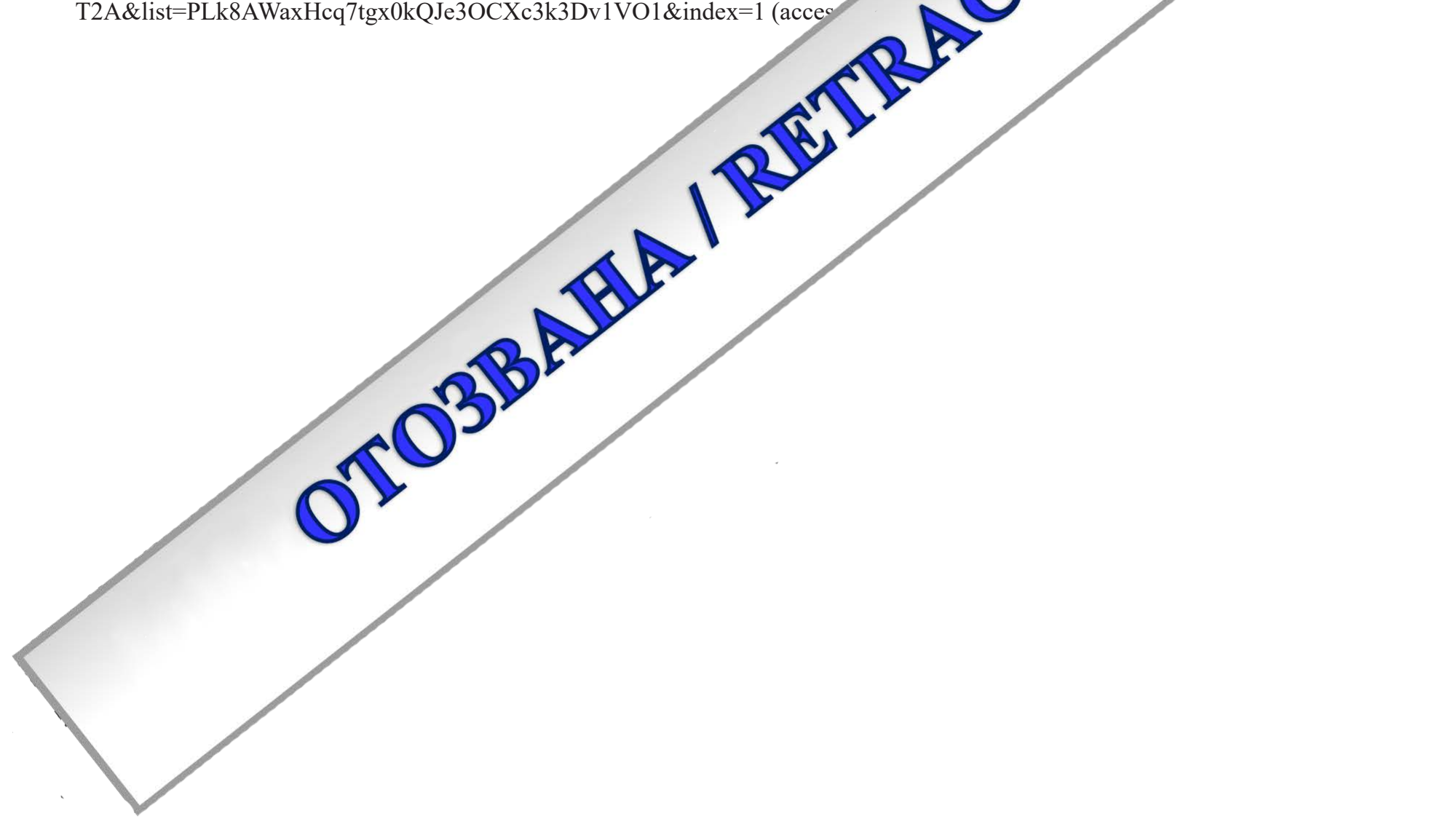

